\title{
Photodegradation of Alizarin Black S Dye Using Zinc Oxide
}

\author{
Haydar Mohammad Salim \\ Department of Chemistry, Faculty of Science, University of Zakho, Duhok 42002, Iraq
}

\begin{abstract}
Zinc oxide ( $\mathrm{ZnO})$ has been used as heterogeneous catalyst for the degradation of Acid Alizarin Black S dye (AAB) in aqueous solutions using UV light irradiation. Experiments were conducted at various operating parameters. The operating parameters were amount of catalyst (50 mg, $100 \mathrm{mg}$ and $150 \mathrm{mg}$ ), initial concentration of dye (30 mg/L, $50 \mathrm{mg} / \mathrm{L}$ and $70 \mathrm{mg} / \mathrm{L}$ ), the $\mathrm{pH}$ of solution (2, 4, 6, 8, 10 and 12) and the UV light intensity (6 watt and 12 watt). The progress of the degradation reaction was monitored spectrophotometrically. It was found that the degradation process of AAB solution was accelerated with increased catalyst dosage and decreased initial concentration of AAB. It was also found that the removal efficiency of AAB significantly depend on $\mathrm{pH}$ value of solution. The results show that the degradation percent reaches the highest values with $\mathrm{pH}$ close to neutral. The data proved that removal percent of dye decreased when 6 watt lamp used instead of 12 watt lamp. The kinetic study confirmed that photocatalytic degradation of $\mathrm{AAB}$ dye follows a pseudo first order reaction rate.
\end{abstract}

Key words: Photodegradation, dyes, ZnO, AOPs, wastewater.

\section{Introduction}

In textile industries, large amount of dyes are lost to the effluents throughout manufacturing and processing operations [1]. These dye effluents, due to the presence of metals and other chemicals in their structure, are either toxic or carcinogenic and mutagenic [2]. Therefore, many new treatments are required for either removal of dyes or converting them to harmless compounds in water. Various studies have been carried out for physical, chemical and biological treatment of effluents containing dyes [3-6]. Among these, adsorption, ozonation, chlorination and biodegradation are the most commonly used methods. Since their complexity and synthetic origin, most of dyes are difficult to biodegrade [6]. Physical methods, on the other hand, such as adsorption, reverse osmosis and flocculation are not destructive methods [4]. Moreover, chemical treatment using ozone or chlorine has led to more successful results, but they are still not

Corresponding author: Haydar Mohammad Salim, master, main research field: advanced oxidation processes. E-mail: haydar.kovly@gmail.com. economically viable [3].

A series of novel methods, during the last decade, for water and wastewater purification have received increasing attention, which called Advanced Oxidation Processes (AOPs). These processes involve hydroxyl radical generation in adequate amount to affect water treatment [7]. UV light with hydrogen peroxide has produced encouraging results of color removal from dye containing waters [5]. Heterogeneous photocatalytic degradation has emerged a significant destructive method leading to the total mineralization of most of the organic contaminants including dyes [8-11]. This process uses semiconductors as a photocatalysts such as $\mathrm{ZnO}$ and $\mathrm{TiO}_{2}$, which are nontoxic, inexpensive, largely available and causes total mineralization of organic substances to water, carbon dioxide and mineral acids [12].

The effectiveness of the semiconductors as a photocatalyst relies on how well the radiation wavelength used matches with the band gap excitation energy of the semiconductor [13, 14]. In recent years, $\mathrm{ZnO}$ was investigated as a potential photocatalyst. For dyes degradation, $\mathrm{ZnO}$ was found to be more efficient 
catalyst than other semiconductors [15-17]. Furthermore, degradation of dyes on coupled semiconductors was investigated to show higher photocatalytic activity [18].

In the present work, $\mathrm{ZnO}$ has been used as a photocatalystin the degradation of $\mathrm{AAB}$ dye in aqueous suspensions of $\mathrm{ZnO}$. In this study, effect of operating parameters such as dye concentration (30 $\mathrm{mg} / \mathrm{L}, 50 \mathrm{mg} / \mathrm{L}$ and $70 \mathrm{mg} / \mathrm{L}$ ), ZnO loading (50 mg, $100 \mathrm{mg}$ and $150 \mathrm{mg})$, effect of $\mathrm{pH}(2-12)$ and light intensity ( 6 watt and 12 watt). Moreover, the kinetics of the degradation reaction was then investigated to optimize the process under constant conditions of $\mathrm{ZnO}$ loading and initial dye concentration.

\section{Material and Methods}

\subsection{Materials}

Acid Alizarin Black (AAB) was purchased from Hopkin and Williams LTD, UK and used as received. A stock solution of AAB $(1,000 \mathrm{mg} / \mathrm{L})$ was prepared on a daily basis in distilled water and other concentrations ( $30 \mathrm{mg} / \mathrm{L}, 50 \mathrm{mg} / \mathrm{L}$ and $70 \mathrm{mg} / \mathrm{L}$ ) were prepared by dilution the stock solution of AAB. The prepared stock solution was covered by aluminum foil and kept in dark. UV lamps with $254 \mathrm{~nm}$ (6 watt and 12 watt) were purchased from SEMTEC, China. Zinc oxide ( $\mathrm{ZnO})$ was purchased from Alpha Chemika, India. Nitric acid $\left(\mathrm{HNO}_{3}\right)$ and sodium hydroxide $(\mathrm{NaOH})$ were purchased from Fisher-Scientific, UK. Various molarities of $\mathrm{HNO}_{3}$ and $\mathrm{NaOH}$ were used to adjust the $\mathrm{pH}$ value of solutions between 2 and 11 using $\mathrm{pH}$ meter.

\subsection{Experimental Procedure}

A closed semi-batch reactor was used in this study as shown in Fig. 1. A $500 \mathrm{~mL}$, at a specific concentration, of the $\mathrm{AAB}$ solution was charged into the reactor, this solution prepared from the stock solution by dilution. $\mathrm{ZnO}$ at a specific amount $(50 \mathrm{~mL}$, $100 \mathrm{~mL}$ and $150 \mathrm{~mL}$ ) was added to the AAB solution. The volume of the reactor was $600 \mathrm{~mL}$. It is made from PYREX glass and fitted with a sample port. The reactor was equipped with a plunging tube in which SEMTEC lamps were placed horizontally. A glass syringe with $5 \mathrm{~mL}$ volume was used, at a specific schedule, to collect samples. The $\mathrm{pH}$ values $(2,4,6,9$, and 12) of these solutions were adjusted using $0.1 \mathrm{M}$ $\mathrm{NaOH}$ and $0.1 \mathrm{M} \mathrm{HNO}_{3}$. The $\mathrm{pH}$ of the solution was determined using $\mathrm{pH}$ meter (EUTECH, Malaysia). Visible spectrophotometer (Jenway, 6700) was used to analyse the collected samples.

\section{Results and Discussion}

\subsection{Effect of ZnO Concentration}

The rates of reaction were found to be directly proportional to the amount of catalyst used as shown in Fig. 2. Above $150 \mathrm{mg}$ of catalyst, the level of reaction rate reaches maximum value and becomes independent of catalyst quantity and plateau form occurs for curve. The rate of reaction reaches maximum level at $150 \mathrm{mg}$ of optimum quantity of catalyst. At higher amounts of catalyst the region of plateau continue and rate of reaction became constant, where screening effect is generated when the quantity of catalyst is very high. Same results for dyes removal

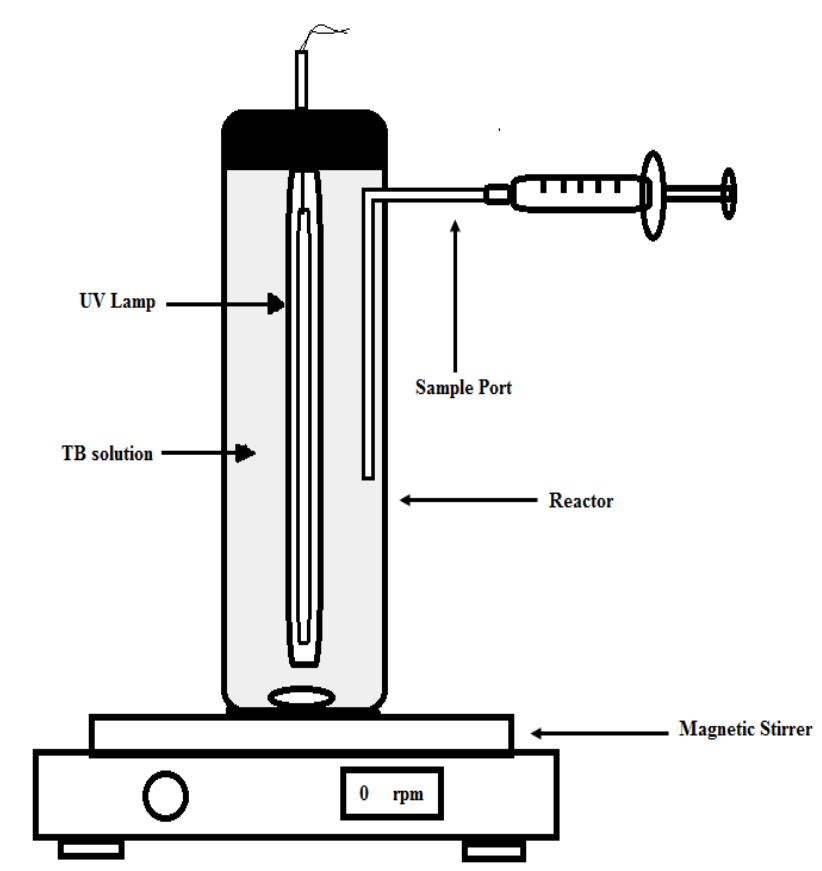

Fig. 1 Photodegradation reactor. 


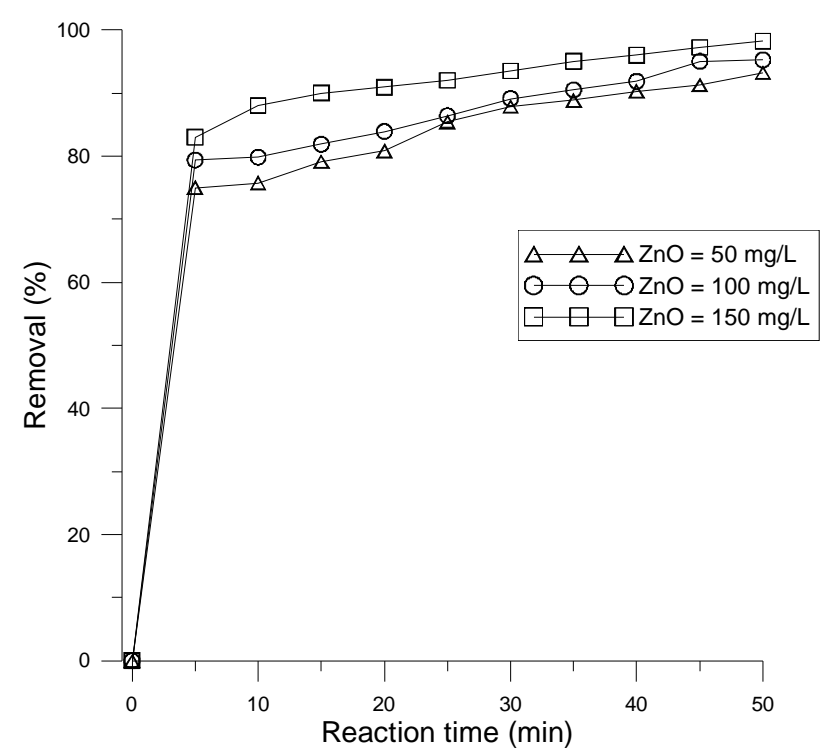

Fig. 2 Effect of catalyst dosage on dye removal ([AAB] = $30 \mathrm{mg} / \mathrm{L}, \mathrm{V}=500 \mathrm{~mL}$ and $\mathrm{pH}=6$ ).

were found for metal oxides such as $\mathrm{TiO}_{2}, \mathrm{ZnO}$ and $\mathrm{Fe}_{2} \mathrm{O}_{3}$ [19-21].

\subsection{Effect of $A A B$ Concentration on Removal Percent}

The effect of $\mathrm{AAB}$ concentration on removal percent was studied in the presence of $\mathrm{ZnO}$ as shown in Fig. 3. The experimental results of $\mathrm{AAB}$ removal were obtained at various concentrations $(30 \mathrm{mg} / \mathrm{L}, 50$ $\mathrm{mg} / \mathrm{L}$ and $70 \mathrm{mg} / \mathrm{L}$ ). It was indicated that the removal percent of dye from solution decreased with increase in initial concentration of dye.

\subsection{Effect of $P H$}

The generation of hydroxyl radicals depends on the $\mathrm{pH}$ of the solution [22]. Therefore, many efforts have been taken to investigate the $\mathrm{pH}$ effect in the photodegradation of organic compounds in the UV irradiation [23]. In this research work, photocatalytic degradation of $\mathrm{AAB}$ dye has been studied at $\mathrm{pH}$ values ranging from 2-12. The relationship between the $\mathrm{pH}$ and the removal percent is shown in Fig. 4. The point of zero charge of $\mathrm{ZnO}$ was found at $\mathrm{pH}$ 6.4. The surface of $\mathrm{ZnO}$ becomes negatively charged under alkaline conditions ( $\mathrm{pH}>6.4)$, whereas, it is positively charged in acidic medium $(\mathrm{pH}<6.4)$.
Consequently, higher activity of photocatalytic degradation was predictable at a neutral medium. It was found that removal percent reached maximum at neutral medium, as shown in Fig. 4. Same results were found for degradation of aniline blue dye using $\mathrm{ZnO}$ [24].

\subsection{Effect of UV Light Intensity}

In the photochemical reactions, the initiation rate for the formation of photocatalysis electron-hole is strongly depends on the UV light intensity [25]. As shown in Fig. 5, the effect of UV light intensity was

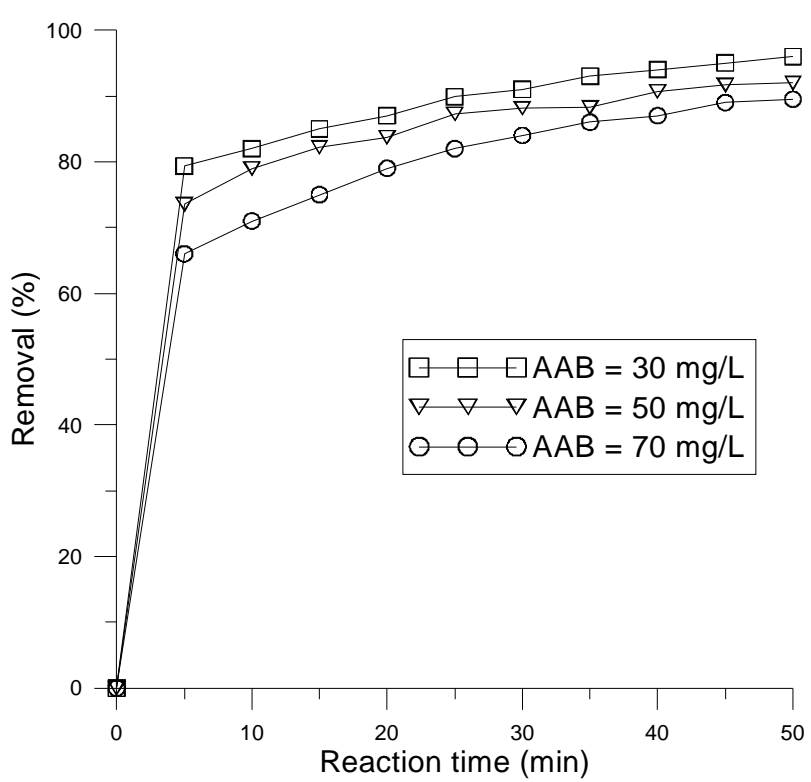

Fig. 3 Effect of initial $\mathrm{AAB}$ concentration $(\mathrm{ZnO}$ amount $=$ $100 \mathrm{mg}, \mathrm{V}=500 \mathrm{~mL}$ and $\mathrm{pH}=6$ ).

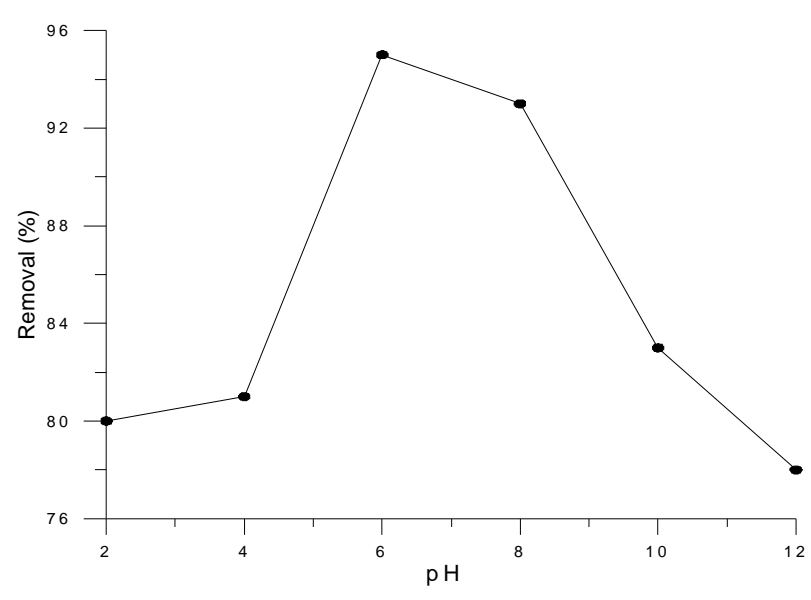

Fig. 4 Effect of $\mathrm{pH}$ on removal percent of $\mathrm{AAB}$ ([AAB] = $30 \mathrm{mg} / \mathrm{L}, \mathrm{ZnO}$ amount $=100 \mathrm{mg}, \mathrm{V}=500 \mathrm{~mL}$ and $\mathrm{pH}=6$ ). 


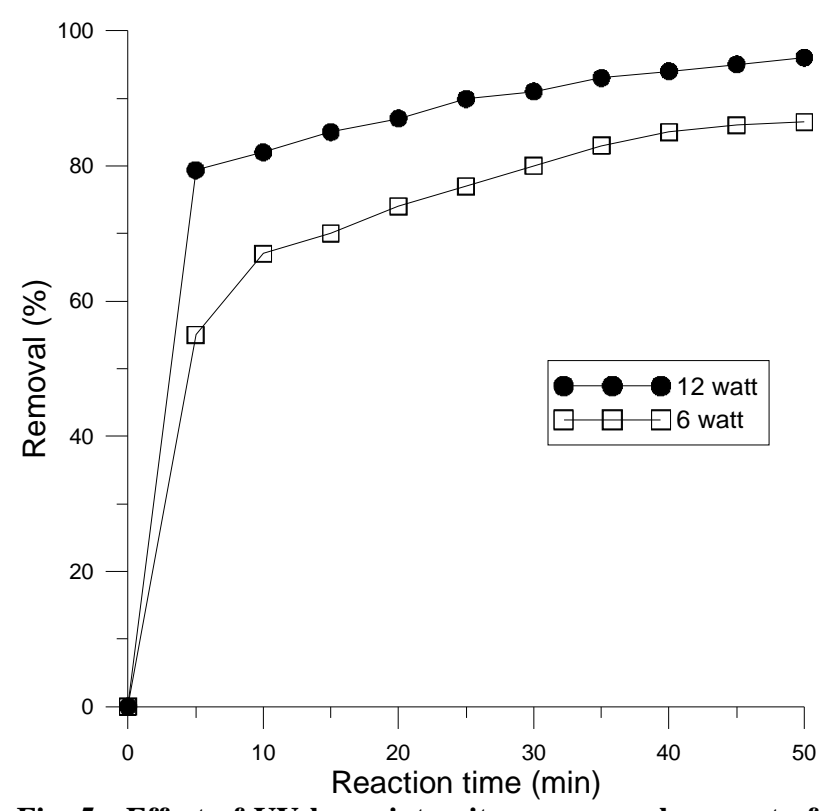

Fig. 5 Effect of UV lamp intensity on removal percent of AAB $([\mathrm{AAB}]=30 \mathrm{mg} / \mathrm{L}, \mathrm{ZnO}$ amount $=100 \mathrm{mg}, \mathrm{V}=500$ $\mathrm{mL}$ and $\mathrm{pH}=6)$.

Table 1 Effect of AAB concentration on a pseudo-first order kinetic for the degradation of $A A B$.

\begin{tabular}{lll}
\hline$[\mathbf{A A B}](\mathbf{m g} / \mathbf{L})$ & $\mathbf{k}^{\prime}\left(\mathbf{m i n}^{-\mathbf{1}}\right)$ & $\mathbf{R}^{\mathbf{2}}$ \\
\hline 30 & 0.068 & 0.90 \\
50 & 0.064 & 0.96 \\
70 & 0.055 & 0.86 \\
\hline
\end{tabular}

investigated using $\mathrm{ZnO}$ as a photocatalyst. The UV lamps used were 6 watt and 12 watt with the wavelength of $254 \mathrm{~nm}$. The results clearly indicated that the 12 watt lamp causes higher rate of degradation for AAB dye as compared to 6 watt lamp. This is due to higher intensity light is suitable for the excitation of many electrons from the valence band of the $\mathrm{ZnO}$ [26]. It has been reported previously that increasing light intensity during photocatalytic degradation reaction, the rate of degradation also increased [27, 28].

\subsection{Kinetic Study}

The rate of degradation increased, as mentioned previously, as the concentration of dye increased from $30 \mathrm{mg} / \mathrm{L}$ to $70 \mathrm{mg} / \mathrm{L}$. The rate constant, $\mathrm{k}$, was found to increase linearly with increasing dye concentration. According to the following equation, the dye loss was observed as a function of time and data were fitted to a pseudo-first order rate model [29]:

$$
\ln \left(\frac{C}{C_{o}}\right)=-k^{\prime} t
$$

The plot of $\ln (\mathrm{C} / \mathrm{Co})$ versus time gives a straight line with $\mathrm{k}^{\prime}=$-slope, so the reaction follows a pseudo-first order scheme. Table 1 shows the effect of dye concentration on the rate constant.

\section{Conclusions}

Photocatalytic degradation of AAB under different operating conditions was investigated in this study in the presence of $\mathrm{ZnO}$ as a photocatalyst. The operating conditions were AAB concentration, quantity of catalyst, $\mathrm{pH}$ and UV light intensity. The photocatalytic degradation of $\mathrm{AAB}$ by using $\mathrm{ZnO}$ as photocatalyst strongly depends on the $\mathrm{AAB}$ concentration and the amount of catalysts. It was found that $\mathrm{AAB}$ removal percent decreased when the $A A B$ concentration increased. However, removal percent increased as the amount of $\mathrm{ZnO}$ increased. The removal percentage reached the maximum value at $\mathrm{pH}$ close to neutral. It was indicated that removal percent of dye decreased when 6 watt lamp used instead 12 watt lamp. The photocatalytic degradation found follow pseudo-first order kinetics in all types of experiments conditions.

\section{References}

[1] Reife, A., and Freeman, H. S. 1996. Environmental Chemistry of Dyes and Pigments. New York: Wiley.

[2] Aksu, Zumriye, and Seyda Sen Cagatay. 2006. "Investigation of Biosorption of Gemazol Turquise Blue-G Reactive Dye by Dried Rhizopus Arrhizus in Batch and Continuous Systems." Separation and Purification Technology 48 (1): 24-35. doi: http://dx.doi.org/10.1016/j.seppur.2005.07.017.

[3] Robinson, T., McMullan, G., Marchant, R., and Nigam, P. 2001. "Remediation of Dyes in Textile Effluent: A Critical Review on Current Treatment Technologies with a Proposed Alternative.” Bioresource Technology 77 (3): 247-255. doi: 10.1016/S0960-8524(00)00080-8.

[4] Akyol, A., Yatmaz, H. C., and Bayramoglu, M. 2004. "Photocatalytic Decolorization of Remazol Red RR in Aqueous ZnO Suspensions.” Applied Catalysis B: Environmental 54 (1): 19-24.

[5] Georgiou, D., Melidis, P., Aivasidis, A., and Gimouhopoulos. K. 2002. "Degradation of Azo-reactive Dyes by Ultraviolet Radiation in the Presence of 
Hydrogen Peroxide.” Dyes and Pigments 52 (2): 69-78. doi: 10.1016/S0143-7208(01)00078-X.

[6] Ledakowicz, S., Solecka, M., and Zylla. R. 2001. "Biodegradation, Decolourisation and Detoxification of Textile Wastewater Enhanced by Advanced Oxidation Processes.” Journal of Biotechnology 89 (2-3): 175-184. doi: 10.1016/S0168-1656(01)00296-6.

[7] Glaze, William, H., Joon-Wun Kang, and Douglas, Chapin, H. 1987. "The Chemistry of Water Treatment Processes Involving Ozone, Hydrogen Peroxide and Ultraviolet Radiation.” Ozone: Science \& Engineering 9 (4): 335-352. doi: 10.1080/01919518708552148.

[8] Saquib, M., and Muneer, M. 2002. "Semiconductor Mediated Photocatalysed Degradation of an Anthraquinone Dye, Remazol Brilliant Blue R under Sunlight and Artificial Light Source.” Dyes and Pigments 53 (3): 237-249. doi: 10.1016/S0143-7208(02)00024-4.

[9] Tanaka, K., Padermpole, K., and Hisanaga, T. 2000. "Photocatalytic Degradation of Commercial Azo Dyes." Water Research 34 (1): 327-333. doi: 10.1016/S0043-1354(99)00093-7.

[10] Hu, C., Meguro, S., and Kawachi, S. 2003. "Cultivation of Shiitake (Lentinula Edodes) on Wood-Meal of Cryptomeria Japonica III. Effect of Water Content of Media on Mycelial Growth.” Mokuzai Gakkaishi/Journal of the Japan Wood Research Society 49 (1): 47-52.

[11] Lachheb, H., Puzenat, E., Houas, A., Ksibi, M., Elaloui, E., Guillard, C., and Herrmann, J. M. 2002. "Photocatalytic Degradation of Various Types of Dyes (Alizarin S, Crocein Orange G, Methyl Red, Congo Red and Methylene Blue) in Water by UV-Irradiated Titania.” Applied Catalysis B: Environmental 39 (1): 75-90. doi: 10.1016/S0926-3373(02)00078-4.

[12] Halmann, M. M. 1995. Photodegradation of Water Pollutants. London: Taylor \& Francis.

[13] Kraeutler, B., and Bard, A. J. 1978. "Heterogeneous Photocatalytic Decomposition of Saturated Carboxylic Acids on $\mathrm{TiO}_{2}$ Powder. Decarboxylative Route to Alkanes.” Journal of the American Chemical Society 100 (19): 5985-5992.

[14] Kamat, P. V. 1993. "Photochemistry on Nonreactive and Reactive (Semiconductor) Surfaces.” Chemical Reviews 93 (1): 267-300.

[15] Lizama, C., Freer, J., Baeza, J., and Mansilla, H. D. 2002. "Optimized Photodegradation of Reactive Blue 19 on $\mathrm{TiO}_{2}$ and $\mathrm{ZnO}$ Suspensions.” Catalysis Today 76 (2-4): 235-246. doi: 10.1016/S0920-5861(02)00222-5.

[16] Daneshvar, N., Salari, D., and Khataee, A. R. 2004. "Photocatalytic Degradation of Azo Dye Acid Red 14 in Water on $\mathrm{ZnO}$ as An Alternative Catalyst to $\mathrm{TiO}_{2}$." Journal of Photochemistry and Photobiology A: Chemistry 162 (2-3): 317-322. doi:
10.1016/S1010-6030(03)00378-2.

[17] Gouvea, C. A. K., Wypych, F., Moraes, S. G., Duran, N., Nagata, N., and Peralta-Zamora, P. 2000. "Semiconductor-Assisted Photocatalytic Degradation of Reactive Dyes in Aqueous Solution.” Chemosphere 40 (4): 433-440. doi: 10.1016/S0045-6535(99)00313-6.

[18] Parra, R., Parada, R., and Rodríguez, M. 2003. "New Approach for the Optimization of Copper Concentrates Flash Combustion by the Control of Blends.” In Yazawa International Symposium: Metallurgical and Materials Processing: Principles and Techologies; High-Temperature Metal Production, 189-198.

[19] Laohaprapanon, Sawanya, Jefunnie Matahum, Lemmuel Tayo, and Sheng-Jie You. 2014. "Photodegradation of Reactive Black 5 in a $\mathrm{ZnO} / \mathrm{UV}$ Slurry Membrane Reactor." Journal of the Taiwan Institute of Chemical Engineers 49 (1): 136-141.

[20] Kadirova, Zukhra, C., Ken-ichi Katsumata, Toshihiro Isobe, Nobuhiro Matsushita, Akira Nakajima, and Kiyoshi Okada. 2014. “Adsorption and Photodegradation of Methylene Blue with $\mathrm{Fe}_{2} \mathrm{O}_{3}$-Activated Carbons under UV Illumination in Oxalate Solution.” Journal of Environmental Chemical Engineering 2 (4): 2026-2036.

[21] Cho, Il-Hyoung, and Kyung-Duk Zoh. 2007. "Photocatalytic Degradation of Azo Dye (Reactive Red 120) in $\mathrm{TiO}_{2} / \mathrm{UV}$ System: Optimization and Modeling Using a Response Surface Methodology (RSM) Based on the Central Composite Design.” Dyes and Pigments 75 (3): 533-543.

[22] Lawless, D., Serpone, N., and Meisel, D. 1991. "Role of Hydroxyl Radicals and Trapped Holes in Photocatalysis. A Pulse Radiolysis Study." The Journal of Physical Chemistry 95 (13): 5166-5170. doi: 10.1021/j100166a047.

[23] Chiron, Serge, Amadeo Fernandez-Alba, Antonio Rodriguez, and Eloy Garcia-Calvo. 2000. "Pesticide Chemical Oxidation: State-of-The-Art.” Water Research 34 (2): 366-377.

[24] Salehi, Kamal, Afshin Maleki, Behzad Shahmoradi, Borhan Mansouri, and Fardin Gharibi. 2014. "Investigation of Photocatalytic Degradation of Reactive Black 5 Dye Using ZnO-CuO Nanocomposite.” Zanko Journal of Medical Sciences 15 (46): 66-74.

[25] Cassano, Alberto, E., and Orlando, Alfano, M. 2000. "Reaction Engineering of Suspended Solid Heterogeneous Photocatalytic Reactors.” Catalysis Today 58 (2-3): 167-197.

[26] Omid Bibak, and Majid Aliabadi. 2014. "Photocatalytic Degradation of Malachite Green in Aqueous Solution Using $\mathrm{TiO}_{2}$ Nanocatalyst.” Journal of Biodiversity and Environmental Sciences (JBES) 5 (4): 301-310.

[27] Torimoto, Tsukasa, Yousuke Aburakawa, Yoichiro 
Kawahara, Shigeru Ikeda, and Bunsho Ohtani. 2004. "Light Intensity Dependence of the Action Spectra of Photocatalytic Reactions with Anatase Titanium (IV) Oxide.” Chemical Physics Letters 392 (1-3): 220-224.

[28] Ahmed, Saber, M. G., Rasul, Wayde, N., Martens, Brown, R., and Hashib, M. A. 2010. "Heterogeneous Photocatalytic Degradation of Phenols in Wastewater: A
Review on Current Status and Developments.” Desalination 261 (1-2): 3-18.

[29] Esplugas, Santiago, Jaime GimEnez, Sandra Contreras, Esther Pascual, and Miguel Rodriguez. 2002. “Comparison of Different Advanced Oxidation Processes for Phenol Degradation.” Water Research 36 (4): 1034-1042. 